\title{
Heterogeneous oxidation of pesticides on the aerosol condensed phase
}

\author{
J. Socorro, A. Durand, B. Temime-Roussel, S. Ravier, \\ S. Gligorovski, H. Wortham \& E. Quivet \\ Aix Marseille Université, CNRS, LCE, France
}

\begin{abstract}
Pesticides are widely used all over the world. It is known that they exhibit adverse health effects and environmental risks due to their physico-chemical properties and their extensive use, which is growing every year. They are distributed in the atmosphere, an important vector of dissemination, over long distances away from the target area. The partitioning of pesticides between the gas and particulate phases influences their atmospheric fate. Most of the pesticides are semi-volatile compounds, emphasizing the importance of assessing their heterogeneous reactivity towards atmospheric oxidants. The photolysis processing and heterogeneous reactivity towards $\mathrm{O}_{3}$ and $\mathrm{OH}$, was evaluated of eight commonly used pesticides adsorbed in silica particles. Silica particles are present in airborne mineral dust in atmospheric aerosols, and heterogeneous reactions can be different in the presence of these mineral particles. Depending on their origin and conditioning, aerosol particles containing pesticides can have complex and highly porous microstructures, which are influenced by electric charge effects and interaction with water vapour. Therefore, the kinetic experiments and consecutive product studies were performed at atmospherically relevant relative humidity (RH) of 55\%. The identification of surface-bound products was performed using GC-(QqQ)-MS/MS and the gas-phase products were monitored on-line by PTRToF-MS. The obtained results will allow a better understanding of the impact of pesticides and their degradation products on human health, and to make recommendations in order to reduce population exposure to the pesticide plume and the pollution by phyto-sanitary products on the regional scale, which constitutes a necessary step in the development of environmental strategies.

Keywords: pesticides, heterogeneous reaction, ozonolysis, hydroxyl radicals, kinetics, degradation products.
\end{abstract}




\section{Introduction}

Pesticides are widely used all over the world to control pests in agricultural production (e.g., wine-producing, arboriculture, gardening, etc.) and in many nonagricultural settings (e.g., home, public spaces, gardens and parks, industrial areas). The important increase in their utilization and their potentially adverse human health effects make their environmental fate a hot topic. A wide variety of pesticides have been detected in the atmosphere throughout the world (Sarigiannis et al. [1]; Shunthirasingham et al. [2]). Once the pesticides reach the atmosphere, they may undergo different transport and transformation processes resulting in the generation of secondary products that could be more hazardous than the primary pesticides (Segal-Rosenheimer and Dubowski [3]; Vera et al. [4]).

The partitioning of pesticides between the gas and particulate phases (Sanusi et al. [5]) influences the atmospheric fate of these compounds such as their direct and indirect photo-chemical degradation. Because of their usually low volatility, pesticides currently used are semi-volatile compounds and are often associated with atmospheric particles (Sanusi et al. [6]; Sauret et al. [7]; Yao et al. [8]). Therefore, beside the photolytic induced degradation of pesticides, their atmospheric fate and lifetime is mostly determined by the heterogeneous reactions with atmospheric oxidants such as ozone $\left(\mathrm{O}_{3}\right)$ and hydroxyl radicals $(\mathrm{OH})$ (Atkinson et al. [9]). However, there are many uncertainties concerning the behavior of the pesticides in the atmosphere. Especially, there is a gap of knowledge regarding the degradation of pesticides induced by heterogeneous reactions. In the past mainly the gas-phase reactivity of pesticides has been considered for the estimation of their atmospheric lifetimes. In order to understand their fate and predict their atmospheric behavior, the degradation of pesticides induced by heterogeneous processing must be further investigated.

The aim of the present work is to study the heterogeneous reactivity of eight commonly used pesticides (cyprodinil, deltamethrin, difenoconazole, fipronil, oxadiazon, pendimethalin, permethrin, and tetraconazole) adsorbed on silica particles towards ozone and hydroxyl radicals, at atmospherically relevant relative humidity (RH) of 55\%. The emerged gas phase and surface bound products were evaluated. The eight studied pesticides are representative of major applications, i.e., insecticides, herbicides, and fungicides, and were chosen for their worldwide utilization but also for their physico-chemical properties such as vapour pressure and the availability of their toxicological data (acceptable daily intake, which is based on ingestion exposure). To the best of author's knowledge there is no information in the literature regarding the inhalation exposure of the studies pesticides. The obtained results will allow better understanding of the impact of pesticides and their degradation products on human health, and to make recommendations in order to reduce population exposure to the pesticide plume and the pollution by phyto-sanitary products on the regional scale, which constitutes a necessary step in the development of environmental strategies. 


\section{Experimental method}

\subsection{Silica particle coatings}

The standards of the following pesticides: cyprodinil (purity 99.8\%), deltamethrin (99.7\%), difenoconazole (97.0\%), fipronil (97.5\%), oxadiazon (99.9\%), pendimethalin (98.8\%), permethrin (98.3\%), and tetraconazole (99.0\%) were purchased from Sigma-Aldrich (PESTANAL ${ }^{\circledR}$, analytical standard).

In this study, hydrophobic silica particles $\left(\mathrm{SiO}_{2}\right.$ content $\left.\geq 99.8 \%\right)$ AEROSIL R812 (Degussa) with, an average primary particle size of $7 \mathrm{~nm}$ and a specific surface area of $260 \pm 30 \mathrm{~m}^{2} \mathrm{~g}^{-1}$ were used. These particles were coated with the pesticides according to a liquid/solid adsorption. $5 \mathrm{~mL}$ of a pesticide solution at $20 \mathrm{mg} \mathrm{l}^{-1}$ in dichloromethane (HPLC-grade, $\geq 99.8 \%$, Sigma-Aldrich) was mixed with $500 \mathrm{mg}$ of silica particles in a Pyrex bulb of $500 \mathrm{~cm}^{3}$ wrapped with aluminium foil to prevent any photo-degradation. This bulb was ultrasonicated and dichloromethane was evaporated by a rotary evaporator (Rotavapor R-114, Büchi) at $40^{\circ} \mathrm{C}$ and $850 \pm 85$ mbar.

\subsection{Ozonolysis experiments}

The heterogeneous processing takes place in a modified rotary evaporator (Laborota 4000 efficient, Heidolph) where the dried coated silica particles were rotated in a Pyrex bulb of $500 \mathrm{~cm}^{3}$ and wrapped with aluminium foil. The system was placed in a thermostated water bath to keep a constant temperature at $(25 \pm 1)^{\circ} \mathrm{C}$ (Figure 1, Part A).

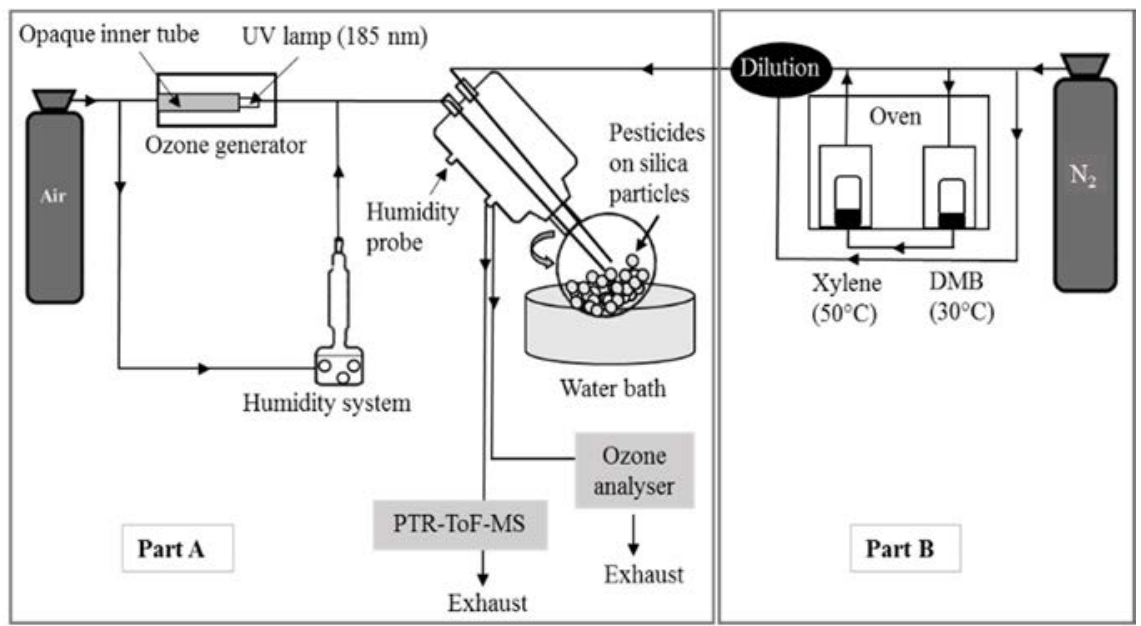

Figure 1: Experimental set-up to assess: Part A - the ozonolysis experiments and Part $\mathrm{A}$ and $\mathrm{B}$ - the $\mathrm{OH}$ radical reactivity. 
The rotation of the bulb ensured an homogeneous exposure of the particles during the experiment. Ozone was generated by passing a constant flow of purified air (zero air generator ZA-1500, F-DGS) through an ozone generator (UVP, LLC Upland, UK). An exposure of air to ultraviolet (UV) radiation at $185 \mathrm{~nm}$ emitted by a mercury vapor pen lamp allowed the ozone generation. Various ozone concentrations were obtained by exposing the air stream to various lengths of the mercury pen lamp. Silica particles coated with pesticides were exposed to different mixing ratios of ozone ranging from 215 ppb to 977 ppb. Each experiment was performed at constant ozone mixing ratios. Ozone mixing ratios were monitored on-line by a photometric ozone analyser $\left(\mathrm{O}_{3} 41 \mathrm{M}\right.$, Environment $\left.\mathrm{SA}\right)$ as shown in Figure 1. During the experiments, the ozone levels were monitored continuously. To avoid a loss of ozone due its solubility in water, a separate humidified air flow was necessary to keep the humidity constant at $(55 \pm 5) \%$ for all the experiments. The relative humidity was measured throughout all experiments with a humidity probe (Hydrolog NT, Rotronic, USA). The silica particles coated with pesticides were exposed during a period of 26 hours.

\section{$2.3 \mathrm{OH}$ radical reactions}

In order to generate $\mathrm{OH}$ radicals in the gaseous phase, the ozonolysis of 2,3-dimethyl-2-butene (DMB > 99\% Sigma Aldrich) under dark conditions was used (Figure 1, Parts A and B). This method was previously used and validated by Pflieger et al. [10].

A DMB flow was generated using a permeation chamber (Figure 1 Part B). A pure $\mathrm{N}_{2}$ (Nitrogen generator) constant flow continuously flushed the Teflon porous cell itself positioned in a permeation flask heated at $30^{\circ} \mathrm{C}$ to maintain a constant generation. Simultaneously, a gaseous tracer, xylene ( $>99.5 \%$ Sigma Aldrich) was used to determine the $\mathrm{OH}$ radical concentrations. Xylene was generated in the same manner as $\mathrm{DMB}$ using a permeation chamber at $50^{\circ} \mathrm{C}$ supplied by a $\mathrm{N}_{2}$ flow. Both DMB and xylene flows were diluted by a controlled $\mathrm{N}_{2}$ flow before reaction chamber (Figure 1, Part B). Ozone was generated as previously explained (Figure 1, Part A) and the ozone concentrations were monitored online. Ozone and DMB react directly inside the reaction chamber to form $\mathrm{OH}$ radicals and xylene allows to determine the $\mathrm{OH}$ radical concentrations. The silica particles coated with pesticides were exposed during a period of 6 hours.

\subsection{Extraction and pesticide quantification}

Following the ozone and/or $\mathrm{OH}$ radicals exposure, pesticides adsorbed on particles were extracted by accelerated solvent extraction (ASE 300, Dionex). Each $40 \mathrm{mg}$ aliquot of particles was introduced in a stainless-steel cell with an internal standard solution (Triphenyl phosphate, 99.9\%, Sigma-Aldrich).

Afterwards, the extracts dissolved in dichloromethane were concentrated under a nitrogen flow using a concentration workstation (TurboVap II, Biotage). 
The obtained solutions were analysed by gas chromatography coupled to tandem mass spectrometry (GC-(QqQ)-MS/MS), with a Trace GC Ultra (Thermo Scientific) coupled to a TSQ Quantum ${ }^{\mathrm{TM}}$ Triple Quadrupole (Thermo Scientific) using electron impact ionisation $(70 \mathrm{eV})$ according to the following parameters: column THERMO TG-5MS (internal diameter $0.25 \mathrm{~mm}$, length $30 \mathrm{~m}$, film thickness $0.25 \mu \mathrm{m}$ ), carrier gas: helium with $1 \mathrm{~mL} \mathrm{~min}^{-1}$ flow rate, split/splitless injector: splitless time of 2 min with surge pressure of $300 \mathrm{kPa}$ during $2 \mathrm{~min}$, injection volume: $1 \mu \mathrm{L}$, inlet temperature: $250^{\circ} \mathrm{C}$, interface temperature: $330^{\circ} \mathrm{C}$, with the following temperature program: hold $3 \mathrm{~min}$ at $75^{\circ} \mathrm{C}$; increase temperature to $180^{\circ} \mathrm{C}$ at a rate of $25^{\circ} \mathrm{C} \mathrm{min}^{-1}$; increase temperature to $300^{\circ} \mathrm{C}$ at $5^{\circ} \mathrm{C} \mathrm{min}{ }^{-1}$; hold 3 min at $300^{\circ} \mathrm{C}$.

During the experiments, a PTR-(ToF)-MS (Proton-Transfer-Reaction Mass Spectrometry, Ionicon Analytik) was connected to the outlet of the reactor. This system was used to continuously monitor the concentrations of DMB and xylene and to detect the gas-phase degradation products of pesticides with a time resolution of $1 \mathrm{~min}$. Parameters of the PTR-ToF-MS during the experiments were as follow: ionization $\mathrm{H}_{3} \mathrm{O}^{+}, \mathrm{E} / \mathrm{N}=130 \mathrm{Td}$, $\mathrm{U}_{\text {drift }}=544.5 \mathrm{~V}, \mathrm{~T}_{\text {drift }}=50^{\circ} \mathrm{C}, \mathrm{P}_{\text {drift }}=$ 2.04 mbar. $U_{\text {drift }}$ is the electric potential applied to the drift tube; $T_{\text {drift }}$ and $P_{\text {drift }}$ are the temperature and the pressure in the drift tube, respectively. $\mathrm{E}$ is the strength of the electrical field in $\mathrm{V} \mathrm{cm}^{-1}$ and $\mathrm{N}$ is the gas number density in $\mathrm{cm}^{3}$. The ratio $\mathrm{E} / \mathrm{N}$ in Townsend ( 1 Townsend $=10^{-17} \mathrm{~cm}^{2} \mathrm{~V}^{-1}$ ) is a defining characteristic of the drift tube.

\section{Results and discussion}

\subsection{Ozonolysis experiments}

\subsubsection{Kinetics study}

An experiment in the absence of ozone was carried out during 26 hours. There was no evidence for hydrolysis or desorption of pesticides under study from the particles.

The pseudo-first-order reaction rate constants for the heterogeneous ozonolysis were determined by analyzing the corresponding exponential decay profiles with respect to the six different ozone mixing ratios from 215 to $977 \mathrm{ppb}$. Figure 2 presents an example of the temporal profiles of the eight pesticides under study at ozone mixing ratio of $930 \mathrm{ppb}$. No significant degradation was observed for four of them, i.e., fipronil, oxadiazon, tetraconazole and difenoconazole. Under these conditions, significant losses were observed for the other four pesticides from the slowest to the fastest: pendimethalin $<$ permethrin $<$ deltamethrin $<$ cyprodinil (Figure 2).

The obtained pseudo-first order rate constants of the four degraded pesticides due to ozone reaction allowed (Socorro et al. [11]) to determine the second order rate constants. Both kinetic patterns were used for this purpose: Langmuir-Rideal (L-R) mechanism (Palm et al. [12, 13]; Pflieger et al. [14-16]; Yang et al. [17]) and Langmuir-Hinshelwood (L-H) mechanism (Pflieger et al. [14-16]). 
The obtained rate constants for L-R mechanism span in the same order of magnitude for the four pesticides under study which react with ozone, i.e., between $3.4 \times 10^{-19} \mathrm{~cm}^{3}$ molecules ${ }^{-1} \mathrm{~s}^{-1}$ and $8.8 \times 10^{-19} \mathrm{~cm}^{3}$ molecules ${ }^{-1} \mathrm{~s}^{-1}$.

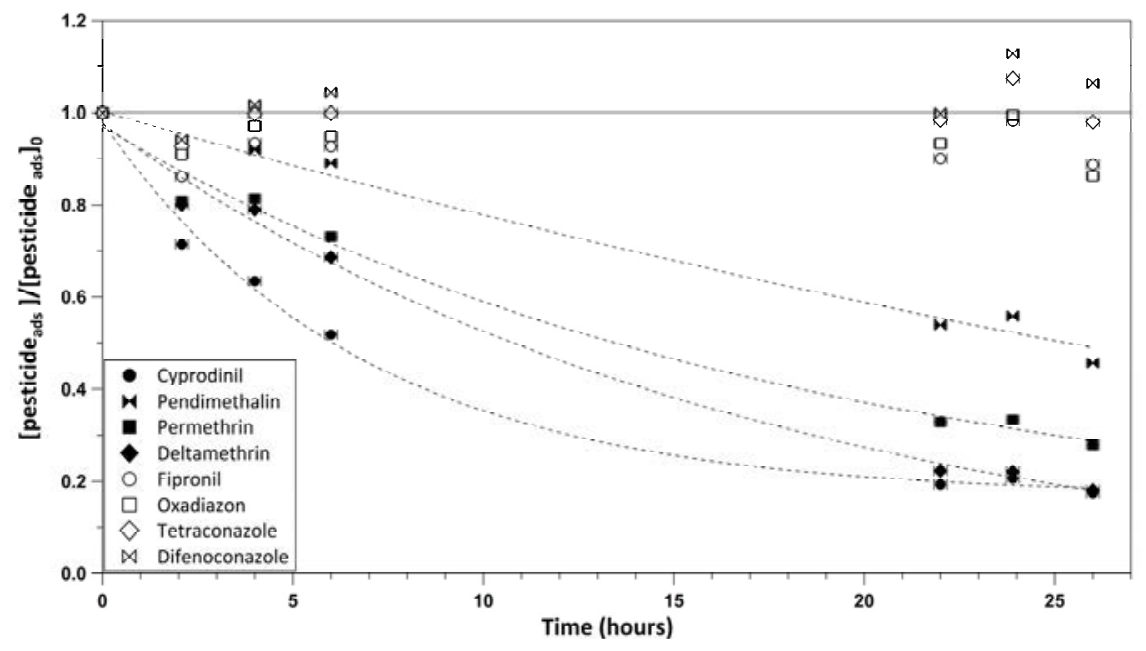

Figure 2: Decays of normalized concentrations of 8 studied pesticides for an ozone mixing ratio of $930 \mathrm{ppb}$ during the ozonolysis experiments. Dotted curves represent the exponential fit of points.

Concerning the L-H mechanism, the adsorption equilibrium, typically manifested by the air-silica partitioning coefficient $\mathrm{K}\left(\mathrm{O}_{3}\right)$, exhibit values between $20.8 \times 10^{-16} \mathrm{~cm}^{3}$ molecules $^{-1}$ and $358 \times 10^{-16} \mathrm{~cm}^{3}$ molecules $^{-1}$, reporting the difficulty of modeling by L-H mechanism (Socorro et al. [11]). The $\mathrm{k}_{(\max )}$ values, i.e., the maximum rate constant that may be attained, range between $0.42 \times 10^{-4}$ and $1.7 \times 10^{-4} \mathrm{~s}^{-1}$. It is difficult to choose between these two models because the L-R model is actually a special case of the L-H model. Hence, both models seem to adequately describe the kinetic pattern of the pesticides under study in agreement with literature reports (Pflieger et al. [14-16]).

The predicted atmospheric lifetimes with respect to a realistic atmospheric ozone mixing ratio of $40 \mathrm{ppb}$ (Vingarzan et al. [18]), are very similar for both models, with lifetimes for L-R mechanism $13 \leq$ lifetime $\leq 35$ days and for L-H mechanism $8 \leq$ lifetime $\leq 33$ days. Atmospheric lifetimes of cyprodinil, deltamethrin and permethrin are higher than one week and higher than one month for pendimethalin, fipronil, tetraconazole, oxadiazon and difenoconazole which suggests inclusion of these pesticides in the persistent organic pollutants (POP). For more details see Socorro et al. [11]. 


\subsubsection{Degradation products}

Formation of gas- and particle-phase products was investigated by PTR-(ToF)MS, and GC-(QqQ)-MS/MS, respectively. So far, among the four pesticides that were found to react with ozone, only one degradation product of deltamethrin was identified in particle phase as 3-phenoxybenzaldehyde (3-PBA). The identification was confirmed with a commercial standard (98\%, Sigma-Aldrich). It seem however that 3-PBA is not a first generation product. Further analysis would give more information about this reaction product.

It is known however that 3-phenoxybenzaldehyde is a toxic compound which interacts with cellular estrogen receptors (McCarthy et al. [19]).

The PTR-(ToF)-MS analysis suggests the formation of bromophosgene $\left(\mathrm{Br}_{2} \mathrm{CO}\right)$ and phosgene $\left(\mathrm{Cl}_{2} \mathrm{CO}\right)$ in the gas-phase which result from the cleavage of alkene double bonds of deltamethrin and permethrin, respectively. SegalRosenheimer and Dubowski [3] have already observed the formation of $\mathrm{Cl}_{2} \mathrm{CO}$ during the ozonolysis of another pyrethroid pesticide that is cypermethrin.

Phosgene found as a degradation product during the ozonolysis of permethrin, is extremely toxic for a short exposure time (USEPA [20]). On a similar basis bromophosgene would probably pose toxicity risk.

The occurrence of these products does raise the real need for additional knowledge regarding the heterogeneous degradation processes of pesticides in particular in indoor atmosphere where several families of pesticides such as pyrethroids, (here, deltamethrin and permethrin) can be found. A possible accumulation in poorly ventilated indoor environments ought to be considered (Vesin et al. [21]).

\subsection{Reactivity of hydroxyl radicals}

\subsubsection{Kinetic study}

A high ozone level was used in these experiments ( $\sim 7 \mathrm{ppm})$ as explained in the experimental section, to generate the required concentrations of $\mathrm{OH}$ radicals. An experiment in absence of $\mathrm{OH}$ radicals was carried out during 8 hours and there was no evidence for degradation of the pesticides in the presence of xylene and DMB. Figure 3 displays the first order decays of the studied pesticides obtained for an $\mathrm{OH}$ concentration of $1.410^{8} \mathrm{~cm}^{-3}$.

Under these conditions, four out of eight pesticides, i.e., fipronil, oxadiazon, tetraconazole and difenoconazole were not significantly degraded. These are the same pesticides that do not react with ozone (see 3.1.1 Kinetics study). As a result, most likely they remain for a prolonged period of time in the atmosphere if they are not transformed under sunlight action.

The other four pesticides were degraded in the following manner from the slowest to the fastest: pendimethalin < permethrin < deltamethrin < cyprodinil. The $\mathrm{OH}$ kinetic experiments are ongoing in our lab to determine the second order rate constants and to detect and identify the secondary products in the gas phase and in the particulate phase, as well. 


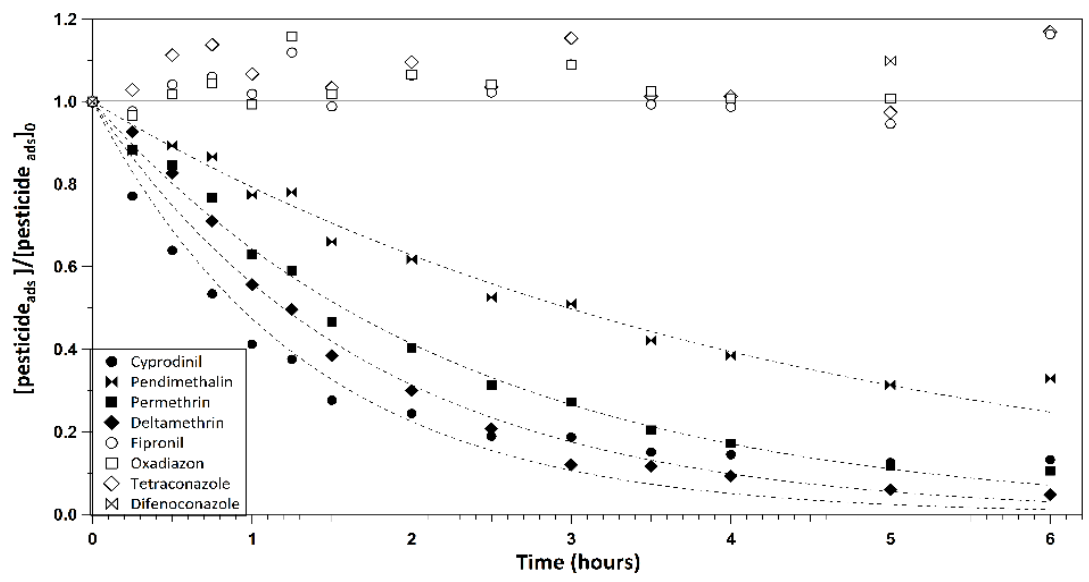

Figure 3: Decays of normalized concentrations of eight studied pesticides for an $\mathrm{OH}$ concentration of $1.4 \times 10^{8} \mathrm{~cm}^{-3}$ due to both $\mathrm{OH}$ and $\mathrm{O}_{3}$ reactivity. Dotted curves represent the exponential fit of the experimental points.

\section{Conclusion}

The rate constants for heterogeneous ozonolysis of eight pesticides adsorbed on silica particles have been determined for ozone mixing ratios ranging from 215 to $977 \mathrm{ppb}$ at 55\% RH. In our experimental conditions, fipronil, oxadiazon, tetraconazole and difenoconazole showed no degradation in the presence of ozone while deltamethrin, permethrin, cyprodinil and pendimethalin were degraded after $26 \mathrm{~h}$ of ozone exposure. Both Langmuir-Rideal and Langmuir-Hinshelwood models exhibit comparable reactivity, leading to similar lifetimes of the studied pesticides.

The estimated atmospheric lifetimes of cyprodinil, deltamethrin and permethrin are higher than one week and higher than one month for pendimethalin, fipronil, tetraconazole, oxadiazon and difenoconazole. These results suggest that the heterogeneous ozonolysis is a very slow process with respect to the studied pesticides.

At the present, only three by-products were clearly identified as 3-phenoxybenzaldehyde (particle phase) and bromophosgene (gas phase) regarding the deltamethrin and phosgene (gas phase) for permethrin. All these products are already known for their toxicity. The occurrence of this products suggests further evaluation of the heterogeneous reactivity of pesticides.

The reactivity of pesticides towards hydroxyl radicals was evaluated for a period of $6 \mathrm{~h}$. Four pesticides were not significantly degraded during $\mathrm{OH}$ radicals exposure, i.e, fipronil, oxadiazon, tetraconazole and difenoconazole. On the other hand, the presence of $\mathrm{OH}$ radicals induced degradation of the other four pesticides, i.e., pendimethalin, permethrin, deltamethrin and cyprodinil. 
The obtained results strongly indicate that difenoconazole, fipronil, oxadiazon and tetraconazole can be classified as persistent organic pollutants with respect to the $\mathrm{OH}$ and ozone heterogeneous reactivity. The other four considered pesticides in this study i.e., cyprodinil, deltamethrin, permethrin and pendimethaline, seem to be persistent regarding their reactivity towards ozone. The experiments with $\mathrm{OH}$ radicals are ongoing to assess their persistence in the atmosphere and determine their lifetimes. In conclusion, these pesticides pose serious air pollution problem since they can be transported over long distances in the atmosphere. Moreover, the identified reaction products exhibit adverse health effects.

In order to comprehensively understand their fate, their impacts and predict their atmospheric behavior, future studies should be focused on the pesticide's degradation induced by photolysis processes, an important degradation pathway during the day and reactions with $\mathrm{NO}_{3}$ radical which is the main oxidant during the night.

\section{Acknowledgements}

This work has been carried out thanks to the support of the A*MIDEX project (no. ANR-11-IDEX-0001-02) funded by the "Investissements d'Avenir" French Government program, managed by the French National Research Agency (ANR). The authors gratefully acknowledge the MASSALYA instrumental platform (Aix Marseille Université, lce.univ-amu.fr) for the provision of analysis and measurements used in this study.

\section{References}

[1] Sarigiannis, D.A., Kontoroupis, P., Solomou, E.S., Nikolaki, S., Karabelas, A.J., Inventory of pesticide emissions into the air in Europe. Atmospheric Environment, 75, pp. 6-14, 2013.

[2] Shunthirasingham, C., Oyiliagu, C.E., Cao, X., Gouin, T., Wania, F., Lee, S.-C., Pozo, K., Harner, T., Muir, D.C.G., Spatial and temporal pattern of pesticides in the global atmosphere. Journal of Environmental Monitoring, 12, pp. 1650-1657, 2010.

[3] Segal-Rosenheimer, M., Dubowski, Y., Heterogeneous Ozonolysis of Cypermethrin Using Real-Time Monitoring FTIR Techniques. The Journal of Physical Chemistry C, 111, pp. 11682-11691, 2007.

[4] Vera, T., Muñoz, A., Ródenas, M., Vázquez, M., Borrás, E., Marqués, M., Mellouki, A., Treacy, J., Sidebottom, H., Atmospheric fate of hymexazol (5-methylisoxazol-3-ol): Simulation chamber studies. Atmospheric Environment, 45, pp. 3704-3710, 2011.

[5] Sanusi, A., Millet, M., Mirabel, P., Wortham, H., Gas-particle partitioning of pesticides in atmospheric samples. Atmospheric Environment, 33, pp. 4941-4951, 1999.

[6] Sanusi, A., Millet, M., Mirabel, P., Wortham, H., Comparison of atmospheric pesticide concentrations measured at three sampling sites: local, regional and long-range transport. Science of the Total Environment, 263, pp. 263-277, 2000. 
[7] Sauret, N., Wortham, H., Putaud, J.P., Mirabel, P., Study of the effects of environmental parameters on the gas/particle partitioning of current-use pesticides in urban air. Atmospheric Environment, 42, pp. 544-553, 2008.

[8] Yao, Y., Harner, T., Blanchard, P., Tuduri, L., Waite, D., Poissant, L., Murphy, C., Belzer, W., Aulagnier, F., Sverko, E., Pesticides in the Atmosphere across Canadian Agricultural Regions. Environmental Science \& Technology, 42, pp. 5931-5937, 2008.

[9] Atkinson, R., Guicherit, R., Hites, R.A., Palm, W.U., Seiber, J.N., De Voogt, P., Transformations of pesticides in the atmosphere: a state of the art. Water Air \& Soil Pollution, 115, pp. 219-243, 1999.

[10] Pflieger, M., Monod, A., Wortham, H., Heterogeneous Oxidation of Terbuthylazine by "Dark" OH Radicals under Simulated Atmospheric Conditions in a Flow Tube. Environmental Science \& Technology, 47, pp. 6239-6246, 2013.

[11] Socorro J., Gligorovski S., Wortham H., Quivet E., Heterogeneous reactions of ozone with commonly used pesticides adsorbed on silica particles. Atmospheric Environment, 100, pp. 66-73, 2015.

[12] Palm, W.U., Elend, M., Krueger, H.U., Zetzsch, C., OH Radical Reactivity of Airborne Terbuthylazine Adsorbed on Inert Aerosol. Environmental Science \& Technology, 31, pp. 3389-3396, 1997.

[13] Palm, W.U., Elend, M., Krueger, H.U., Zetzsch, C., Atmospheric Degradation of a Semivolatile Aerosol-Borne Pesticide: Reaction of $\mathrm{OH}$ with Pyrifenox (an Oxime-Ether), Adsorbed on $\mathrm{SiO}_{2}$. Chemosphere, 38, pp. 1241-1252, 1999.

[14] Pflieger, M., Monod, A., Wortham, H., Kinetic study of heterogeneous ozonolysis of alachlor, trifluralin and terbuthylazine adsorbed on silica particles under atmospheric conditions. Atmospheric Environment, 43, pp. 5597-5603, 2009.

[15] Pflieger, M., Grgić, I., Kitanovski, Z., Nieto, L., Wortham, H., The heterogeneous ozonation of pesticides adsorbed on mineral particles: Validation of the experimental setup with trifluralin. Atmospheric Environment, 45, pp. 7127-7134, 2011.

[16] Pflieger, M., Grgić, I., Kitanovski, Z., Ozonation of isoproturon adsorbed on silica particles under atmospheric conditions. Atmospheric Environment, 61, pp. 40-47, 2012.

[17] Yang, B., Wang, Y., Zhang, W., Liu, C., Shu, X., Shu, J., Heterogeneous ozonolysis of pirimicarb and isopropalin: mechanism of ozone-induced Ndealkylation and carbonylation reactions. Environmental Chemistry, 9, pp. 521-528, 2012.

[18] Vingarzan, R., A review of surface ozone background levels and trends. Atmospheric Environment, 38, pp. 3431-3442, 2004.

[19] McCarthy, A.R., Thomson, B.M., Shaw, I.C., Abell, A.D., Estrogenicity of pyrethroid insecticide metabolites. Journal of Environmental Monitoring, 8, pp. 197-202, 2006.

[20] United States Environmental Protection Agency (USEPA). Toxicological review of phosgene, Online: http://www.epa.gov/iris/toxreviews/0487tr.pdf 
[21] Vesin, A., Quivet, E., Temime-Roussel, B., Wortham, H., Indoor transfluthrin concentration levels during and after application of electric vaporizers using a Proton-Transfer-Reaction Mass Spectrometer. Atmospheric Environment, 65, pp. 123-128, 2013. 